\title{
Erratum to: An analysis of genotype-phenotype correlations and survival outcomes in patients with primary hyperparathyroidism caused by multiple endocrine neoplasia type 1: the experience at a single institution
}

\section{Kiyomi Horiuchi • Takahiro Okamoto • \\ Masatoshi Iihara $\cdot$ Toshihiko Tsukada}

Published online: 27 June 2013

(C) Springer Japan 2013

\section{Erratum to: Surg Today}

DOI 10.1007/s00595-012-0354-y

The original version of this article unfortunately contained the following errors:

In the "Introduction" section, in the 2nd paragraph, the 1st sentence should read:

The locus of the gene responsible for MEN1 was assigned to the long arm of chromosome 11 in 1988 [3].

In the "Methods" section, in the paragraph headed "MEN1 gene", the reference citation numbers should be [22] and [23], and consequently the following entries should be added to the reference list:

22. Shimizu S, Tsukada T, Futami H, Ui K, Kameya T, Kawanaka M, et al. Germline mutations of the MEN1 gene in Japanese kindred with multiple endocrine neoplasia type 1. Jpn J Cancer Res. 1997;88:1029-32.

The online version of the original article can be found under doi:10.1007/s00595-012-0354-y.

K. Horiuchi $(\bowtie) \cdot$ T. Okamoto $\cdot$ M. Iihara

Department of Endocrine Surgery, Tokyo Women's

Medical University, 8-1 Kawada-cho, Shinjuku-ku,

Tokyo 162-8666, Japan

e-mail: horiuchi.kiyomi@twmu.ac.jp

T. Tsukada

Tumor Endocrinology Project, National Cancer Center Research

Institute, Tokyo, Japan
23. Kikuchi M, Ohkura N, Yamaguchi K, Takao Obara T, Tsukada T. Gene dose mapping delineated boundaries of a large germline deletion responsible for multiple endocrine neoplasia type 1. Cancer Lett. 2004;208:81-8. 